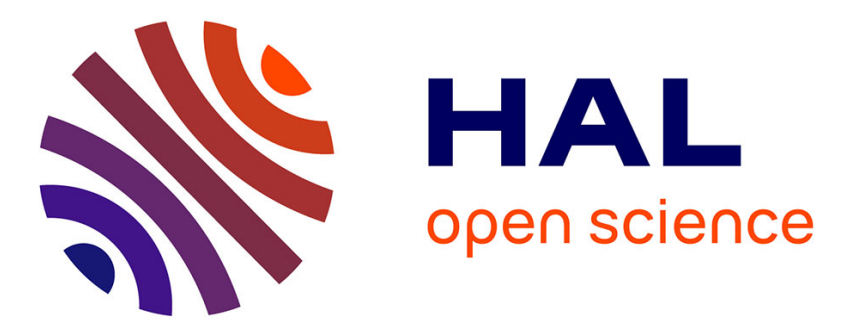

\title{
Methionine supplementation for multi-organ dysfunction in MetRS-related pulmonary alveolar proteinosis
}

\author{
Alice Hadchouel, David Drummond, Clément Pontoizeau, Laura Aoust, \\ Maria-Margarita Hurtado Nedelec, Jamel El-Benna, Elsa Gachelin, Caroline \\ Perisson, Clémentine Vigier, Manuel Schiff, et al.
}

\section{To cite this version:}

Alice Hadchouel, David Drummond, Clément Pontoizeau, Laura Aoust, Maria-Margarita Hurtado Nedelec, et al.. Methionine supplementation for multi-organ dysfunction in MetRS-related pulmonary alveolar proteinosis. European Respiratory Journal, 2021, pp.2101554. 10.1183/13993003.015542021. hal-03447784

\author{
HAL Id: hal-03447784 \\ https://hal.science/hal-03447784
}

Submitted on 24 Nov 2021

HAL is a multi-disciplinary open access archive for the deposit and dissemination of scientific research documents, whether they are published or not. The documents may come from teaching and research institutions in France or abroad, or from public or private research centers.
L'archive ouverte pluridisciplinaire HAL, est destinée au dépôt et à la diffusion de documents scientifiques de niveau recherche, publiés ou non, émanant des établissements d'enseignement et de recherche français ou étrangers, des laboratoires publics ou privés. 
Methionine supplementation for multi-organ dysfunction in MetRS-related pulmonary

alveolar proteinosis

Alice Hadchouel $^{1,2^{*}}, \mathrm{MD}, \mathrm{PhD}$, David Drummond ${ }^{1,2}, \mathrm{MD}, \mathrm{PhD}$, Clément Pontoizeau ${ }^{2,3}, \mathrm{MD}$, PhD, Laura Aoust ${ }^{1,2}$, MD, Maria-Margarita Hurtado Nedelec ${ }^{4,5}$, MD, PhD, Jamel El Benna ${ }^{4}$, $\mathrm{PhD}$, Elsa Gachelin ${ }^{6}, \mathrm{MD}$, Caroline Perisson ${ }^{7}, \mathrm{MD}$, Clémentine Vigier ${ }^{8}$, MD, Manuel Schiff $^{9,10}, \mathrm{MD}, \mathrm{PhD}$, Florence Lacaille ${ }^{11}$, MD, Thierry Jo Molina ${ }^{10,12}, \mathrm{MD}$, PhD, Laureline Berteloot $^{10,13}$, MD, Sylvain Renolleau ${ }^{2,14}$, MD, PhD, Chris Ottolenghi ${ }^{2,3}$, MD, PhD, JeanMarc Tréluyer $^{2,15} \mathrm{MD}, \mathrm{PhD}$, Jacques de Blic ${ }^{1,2}, \mathrm{MD}, \mathrm{PhD}$, and Christophe Delacourt ${ }^{1,2} \mathrm{MD}$, $\mathrm{PhD}$

Prs de Blic and Delacourt contributed equally to this article.

${ }^{1}$ AP-HP, Hôpital Universitaire Necker-Enfants Malades, Service de Pneumologie Pédiatrique, Centre de Référence pour les Maladies Respiratoires Rares de l'Enfant, Paris, France

${ }^{2}$ Université de Paris, Faculté de Médecine, Paris, France

${ }^{3}$ AP-HP, Hôpital Universitaire Necker-Enfants Malades, UF de Métabolomique, Paris, France

${ }^{4}$ Centre de Recherche sur l'Inflammation (CRI), INSERM-U1149, CNRS-ERL8252, Laboratoire d'Excellence Inflamex, Université Paris Diderot-Sorbonne Paris Cité, Faculté de Médecine, Site Xavier Bichat, Paris, France

${ }^{5}$ AP-HP, Centre Hospitalier Universitaire Xavier Bichat, UF Dysfonctionnements Immunitaires, Paris, France

${ }^{6}$ CHU Reunion site Félix Guyon, Service de Pédiatrie, Saint Denis, France

${ }^{7}$ CHU Reunion site Sud, Service de Pédiatrie, Saint Pierre, France

${ }^{8} \mathrm{CHU}$ de Rennes, Service de Pédiatrie, Rennes, France

${ }^{9}$ AP-HP, Hôpital Necker-Enfants Malades, Service de Maladies Héréditaires du Métabolisme, Centre de Référence Maladies Héréditaires du Métabolisme, Paris, France

${ }^{10}$ Institut Imagine, Inserm UMRS 1163, Paris, France

${ }^{11}$ AP-HP, Hôpital Necker-Enfants Malades, Service de Gastroentérologie-HépatologieNutrition Pédiatrique, Paris, France

${ }^{12}$ AP-HP, Hôpital Universitaire Necker-Enfants Malades, Service de Pathologie, Paris, France

${ }^{13}$ AP-HP, Hôpital Universitaire Necker-Enfants Malades, Service d'Imagerie Pédiatrique, Paris, France

${ }^{14}$ AP-HP, Hôpital Universitaire Necker-Enfants Malades, Service de Réanimation médicochirurgicale pédiatrique, Paris, France

${ }^{15}$ Groupe Hospitalier APHP Centre Université de Paris Recherche Clinique et Pharmacologie Necker Cochin, Paris, France

*Corresponding author:

Alice Hadchouel

Service de Pneumologie et d'Allergologie Pédiatriques

Hôpital Universitaire Necker-Enfants Malades

149 rue de Sèvres

75743 Paris Cedex 15

Tél : +33144494847 / 4955 / Fax : +33144381740

alice.hadchouel-duverge@aphp.fr

\section{Take-home message:}


Pulmonary alveolar proteinosis related to mutations in MARS1 is a rare and severe lung disease with early onset and no curative treatment to date. In four affected children we showed that methionine supplementation is an effective treatment. 


\section{ABSTRACT}

Introduction. Pulmonary alveolar proteinosis related to mutations in the methionine tRNA synthetase (MARS1) gene is a severe, early-onset disease that results in death before the age of 2 years in one-third of patients. It is associated with a liver disease, growth failure and systemic inflammation. As methionine supplementation in yeast models restored normal enzymatic activity of the synthetase, we studied the tolerance, safety and efficacy of daily oral methionine supplementation in patients with severe and early disease.

Methods. Four patients received methionine supplementation and were followed for respiratory, hepatic, growth, and inflammation-related outcomes. Their course was compared to those of historical controls. Reactive oxygen species (ROS) production by patient monocytes before and after methionine supplementation was also studied.

Results. Methionine supplementation was associated with respiratory improvement, clearance of the extracellular lipoproteinaceous material, and discontinuation of whole-lung lavage in all patients. The three patients who required oxygen or non-invasive ventilation could be weaned off within 60 days. Liver dysfunction, inflammation, and growth delay also improved or resolved. At a cellular level, methionine supplementation normalized the production of reactive oxygen species by peripheral monocytes.

Conclusion. Methionine supplementation was associated with important improvements in children with pulmonary alveolar proteinosis related to mutations in the MARS1 gene. This study paves the way for similar strategies for other tRNA synthetase deficiencies. 


\section{INTRODUCTION}

Pulmonary alveolar proteinosis (PAP) is characterized by alveolar accumulation of lipoproteinaceous material derived from surfactant [1]. It has multiple causes. We previously described a specific type of PAP prevalent on the island of La Réunion, characterized by an early onset, associated liver involvement, systemic inflammation, frequent progression to lung fibrosis, and poor prognosis [2]. Mortality reached 59\%. Half of the deaths occurred before the age of two years, despite repetitive and frequent whole-lung lavages (WLL) and other treatments, such as high-dose intravenous (IV) steroids that were used in severely affected patients who displayed important inflammation. Mutations in MARS1 were subsequently identified as disease causing [3] and the phenotype was referred as Interstitial Lung and Liver Disease (ILLD) in OMIM (\#615486). MARS1 encodes the cytosolic methionine tRNA synthetase (MetRS), which plays a critical role in protein biosynthesis by charging tRNAs with methionine, leading to the formation of methionyl-tRNA. The double homozygous Ala393Thr/Ser567Leu mutations found in the "Réunion" patients are located in the catalytic domain of MetRS and severely impair growth and enzymatic activity in yeast, which is restored by methionine supplementation [3]. Enzymatic preparations purified from transfected E. coli have confirmed the significant impact of the mutations on the rate of the aminoacylation reaction (reduction of the $k_{\text {cat }}$ by 5 to 6 -fold relative to wild type), especially for methionine affinity, as shown by a significant increase in the $K_{m}$ for methionine in mutants [4]. Patients of other ethnicities have been described, with other mutations but a very similar phenotype [3, 5-10]. As enzymatic activity can be restored by methionine supplementation in yeast, we aimed to treat successive patients with standardized methionine supplementation to assess safety and tolerance of such supplementation, and to compare the evolution of the treated patients to that of our historical cohort. 


\section{MATERIAL AND METHODS}

\section{STUDY DESIGN}

This study was approved by the Comité de Protection des Personnes Est-II (CPP18/11/28/42028) and registered at clinicaltrials.gov (NCT03887169). It aimed to determine the efficacy, safety and tolerance of daily oral supplementation of methionine in patients presenting PAP due to the Ala393Thr/Ser567Leu mutations in MARS1. Patients were referred to the Paediatric Pulmonology Unit at Necker hospital for their care. Written informed consent was obtained from the parents. Outcomes were assessed at 2 months of treatment. The supplementation was pursued if it was efficient and well tolerated. Data are presented at 3 time-point assessments: before starting the supplementation (D0), 2 months after the supplementation was started (M2) and at last follow-up (LFU). In France, methionine has the status of a nutritional supplement and is widely and freely available.

\section{ADMINISTRATION SCHEME}

Methionine was given as L-methionine powder diluted in water and was administrated orally or enterally, every $6 \mathrm{~h}$, starting at $80 \mathrm{mg} / \mathrm{kg} /$ day and progressively increased until obtaining plasma concentrations between 45 and $500 \mu \mathrm{M}$ at residual and peak states ( $1 \mathrm{~h}$ after intake). Methods to determine the doses, targeted ranges and frequency of supplementation are detailed in the Online Supplement.

\section{MEASURED OUTCOMES}

Efficacy of the treatment was evaluated based on the respiratory, hepatic, inflammatory, and growth status. Respiratory assessment included regular clinical evaluation, chest CT at D0, M2 and at LFU, pathological aspects of broncho-alveolar lavage (BAL) fluid, and the possibility to discontinue the WLL. Liver status was assessed by clinical examination, liver 
ultrasound, and liver function tests. Growth and nutritional status were assessed by monitoring growth curves and albuminemia. Systemic inflammation was assessed by measuring CRP, the erythrocyte sedimentation rate, blood neutrophils count and IgG levels. Patients were monitored for potential adverse effects that included liver dysfunction and central nervous system (CNS) abnormalities, especially a risk of cerebral oedema as described in congenital hypermethioninemia when methionine plasma level exceeds $800 \mu \mathrm{M}$ [11]. Other possible adverse events were variations in arterial blood pressure, nausea, vomiting, dizziness and polyuria as described in subjects receiving a loading dose of methionine to study the relationship between homocysteine levels and cardiovascular disease. Those effects were mild and transient [12]. Plasma concentrations of homocysteine, which derived from methionine, were monitored. Supplementation with vitamins B6, B9, and B12 was initiated when homocysteine exceeded $30 \mu \mathrm{M}$ to favour the remethylation of homocysteine back to methionine [13].

\section{COMPARISON TO THE HISTORICAL CONTROLS}

We compared the course of treated patients to that of patients reported by Enaud et al.[2] as well as seven patients who were diagnosed since this publication. All those patients harboured the Ala393Thr/Ser567Leu genotype.

\section{WESTERN BLOT}

MetRS protein expression in PBMCs was assessed by Western blot. Methods are detailed in the Online Supplement. 
Function of peripheral monocytes was assessed by quantifying reactive oxygen species (ROS) production as detailed in the Online Supplement.

\section{STATISTICAL ANALYSES}

For historical controls (HC), data were expressed as median and interquartile range. We computed the difference between the values for each continuous variable at D0 and at LFU for each treated patient, as well as between diagnosis and six months to one year from diagnosis for the HC. Differences were compared between groups using Mann-Whitney tests. For each categorical variable (i.e., weaning from oxygen and enteral nutrition), we compared the proportion of patients who were weaned from such support at the second assessment between groups using Fisher's exact test. A p-value $<0.05$ was considered statistically significant.

\section{RESULTS}

\section{DISEASE COURSE AND EFFICACY OF METHIONINE SUPPLEMENTATION}

The patients' characteristics before treatment are presented in Table 1 and disease course for each patient is summarized in Table 2 .

\section{Patient 1}

P1 was referred to her local hospital at 4 months of age for vomiting, failure to thrive, enlarged liver, and tachypnoea. At that time, chest CT showed only discrete lesions (Figure 1). However, BAL fluid was macroscopically opalescent and its pathological examination confirmed the diagnosis of PAP (Figure 1). Molecular diagnosis of MARS1 mutations was subsequently made. Before starting methionine supplementation, P1 had severe growth failure, hypotonia, required continuous supplemental oxygen, enteral nutrition and experienced chronic vomiting. Laboratory parameters showed anaemia, cholestasis, mild 
elevated AST, hypoalbuminemia, inflammation and high IgG level (Table 2). Ultrasound showed hepatomegaly with hyperechoic parenchyma. Brain MRI was normal. Supplementation with methionine was started at six months of age. She underwent seven therapeutic WLL from D7 to D61 of treatment. She was weaned from oxygen on D42 and enteral nutrition on D54, with resolution of vomiting. On M2, all clinical and biological features were improved (Table 2). Chest CT showed improvement. Echogenicity of the liver normalized. We decided to pursue the treatment. She was discharged home on D71. She was admitted for a new assessment at nine months of age, one month after the last WLL. The BAL showed improvement with total clearance of the extracellular lipoproteinaceous material and a marked decrease in the proportion of vacuolized $\mathrm{ORO}^{+}$macrophages (Figure 1). At the last follow-up ten months later, she was asymptomatic. Her weight had reached the mean on the growth curve (Table 2). There was no neurological impairment neither developmental delay. She was not taking any other treatment apart from methionine $(30 \mathrm{mg} / \mathrm{kg} / 6 \mathrm{~h})$ and no therapeutic WLL had been performed since D61. Treatment every 6h led to reproducible residual and peak values of methionine plasma concentrations (Supplemental Figure S1). Apart from a moderately persistent elevated sedimentation rate, all her laboratory parameters returned to normal (Table 2). Size and echogenicity of the liver normalized. Her chest CT showed very discrete postero-basal ground glass opacities, with no signs of fibrosis (Figure $1)$.

\section{Patient 2}

In P2 MARS1 related PAP was diagnosed at 5 months of age. She had already undergone 25 WLL. She received monthly IV steroid pulses $\left(300 \mathrm{mg} / \mathrm{m}^{2} /\right.$ day for 3 days each) and daily oral steroids from the age of 11 months in order to control her respiratory and inflammatory status. She became steroid-dependent with respiratory relapses when decreasing steroids and 
developed several complications with systemic arterial hypertension and osteoporotic fractures. She was started on mycophenolate mofetil (MMF) at the age of 21 months, which allowed tapering then stopping the steroids at the age of 25 months, and spacing the WLL every six months. She was the first patient treated with MMF. She still showed feeding difficulties, refusing oral feeding, presenting regular vomiting, and requiring total enteral nutrition using a gastrostomy. At the time by which methionine supplementation was started, she had WLL every 6 months, and had been taking MMF for 15 months. She displayed discrete persistent inflammation (slightly elevated values of the sedimentation rate and $\operatorname{IgG}$ ) that resolved at the last follow-up (Table 2). She underwent one WLL that showed only mild lipoproteinaceous material deposition. After 2 months of supplementation with methionine, she was starting to eat by herself and nausea and vomiting disappeared. We decided to pursue the supplementation. After one year of treatment (last follow-up), she showed a significant decrease in her feeding difficulties, along with satisfactory growth (Table 2). Her chest CT, which was already greatly improved after MMF initiation, showed no further changes after methionine supplementation. There were no signs of fibrosis. WLL and MMF were discontinued. She was taking methionine at a dosage of $27 \mathrm{mg} / \mathrm{kg} / 6 \mathrm{~h}$, with reproducible residual and peak values of methionine plasma concentrations (Supplemental Figure S1).

\section{Patient 3}

At diagnosis at 4 months of age, and before starting methionine supplementation, P3 displayed a similar clinical, biological, and pathological presentation as P2 (Table 2 and Figure 1). Her chest CT showed a more pronounced crazy-paving aspect (Figure 1). Ultrasound showed an enlarged liver. Brain MRI showed periventricular cysts. Supplementation with methionine was started at six months of age. She underwent two therapeutic WLL on D16 and D45. Vomiting decreased from D10 and finally ceased on D31. 
She was weaned from oxygen on D47 and enteral nutrition on D71. On M2, all clinical and biological features were improved (Table 2). Control chest CT showed a clear improvement, with regression of posterior consolidations and only persistent scattered subpleural pseudonodular consolidative lesions. The size of the liver decreased on ultrasound. Because of these results, we decided to pursue the treatment. She was discharged home at M2. She was admitted for a new assessment at 11 months old. Clinically, her respiratory and growth status continued to improve. Her chest CT showed new improvement, with almost complete regression of the subpleural pseudonodular consolidations. A subtle very low-density crazypaving pattern remained, with no signs of fibrosis. She underwent a BAL, which showed partial regression of the extracellular abnormal lipoproteinaceous material and a marked decrease in the number of vacuolized $\mathrm{ORO}^{+}$macrophages (Figure 1). Size of the liver normalized on ultrasound. At the last follow-up 5 months later, she had been taking methionine for 10 months with no other treatment. Her current dosage was $28 \mathrm{mg} / \mathrm{kg} / 6 \mathrm{~h}$ with stable methionine plasma concentrations (Supplemental Figure S1). She had no respiratory symptoms and growth status continued to improve (Table 2). She had no neurological impairment nor developmental delay and brain MRI was not controlled. Her chest CT showed new improvement with only discrete lesions (Figure 1).

\section{Patient 4}

In P4 MARS1 related PAP was diagnosed at 3 months of age. Before starting methionine, despite repetitive WLL $(n=19)$ and monthly IV steroid pulses, P4 was severely affected by chronic respiratory insufficiency, requiring continuous non-invasive ventilation (NIV) with oxygen, and growth failure and recurrent vomiting necessitating exclusive parenteral nutrition (Table 2). He had a severe psychomotor delay, was not able to sit without support and vocalized a few syllables. Laboratory parameters showed anaemia, cholestasis, 
hypoalbuminemia, inflammation and high IgG level. He was dependent on blood transfusions and albumin perfusions. Liver was enlarged and hyperechoic on ultrasound. Chest CT showed a crazy-paving appearance, with an increasing posterior and inferior gradient of density, along

with microcystic lesions suggestive of early-stage fibrosis (Figure 1). Brain MRI was normal on two occasions. The last WLL and the last IV steroids pulses had been performed one month before the beginning of methionine supplementation. After starting methionine at 21 months of age, he was weaned from NIV on D38, with a progressive decrease in oxygen supply. He was weaned from parenteral nutrition on D87. The last blood transfusion and albumin perfusion were performed on D79 and D56, respectively. A chest CT performed after two months of treatment showed a marked decrease in the density and extension of consolidations, microcystic lesions remained stable. On ultrasound, size of the liver was stable but echogenicity returned to normal. The patient has not undergone therapeutic WLL nor received steroids or other treatment since the beginning of methionine supplementation. At the last follow-up at 33 months of age, he was taking methionine at a dosage of $20 \mathrm{mg} / \mathrm{kg} / 6 \mathrm{~h}$ with stable plasma concentrations (Supplemental Figure S1). There was a marked catch-up in growth, his anaemia and cholestasis had resolved, the albumin plasma levels had improved. He was completely weaned off oxygen. He has started to eat by himself. There was also a catch-up in psychomotor milestones as he had a vocabulary of more than ten words, understand and followed simple directions, and walks. Chest CT showed further improvement with an important regression of consolidations, microcystic lesions remained stable.

\section{COMPARISON TO THE HISTORICAL CONTROLS}

The cohort of $\mathrm{HC}$ included 41 patients. Twenty-five (61\%) died at a median age of 3.5 years [1.1-16.5] from terminal respiratory failure. We compared the course of treated patients from D0 ("M0") to LFU ("M6-M12") to that of the HC from diagnosis ("M0") to six months to one 
year of progression of the disease or at the last evaluation if they died within six months of diagnosis ("M6-M12"). First time point considered for the HC was diagnosis because it corresponds to the beginning of WLL that used to be the standard of care for those patients. Thus, for patients treated with methionine and for the HC, initial data correspond to status before starting treatment. Among the HC, data were available for comparison at the two assessment points for 20 (11 of which are dead). Their characteristics at diagnosis were similar to those of the patients treated with methionine. The median age at diagnosis was four months [3.3-6.8]. During the course of their disease, they were treated by repetitive WLL alone $(n=9 / 20)$ or by WLL and systemic steroids $(n=11 / 20)$. The median number of therapeutic WLL from diagnosis to the second assessment was 13 [10-19]. No patient received MMF. At diagnosis, 15 patients required supplemental oxygen and 18 enteral nutrition. Before starting methionine, 3 patients required oxygen and 4 an enteral or parenteral nutrition. At the second assessment, 1/15 had been weaned off oxygen and none off enteral nutrition, versus $3 / 3$ patients treated with methionine for oxygen and 2/4 for enteral nutrition ( $\mathrm{p}=0.005$ for oxygen weaning, $\mathrm{p}=0.026$ for enteral nutrition weaning). Among the five $\mathrm{HC}$ who did not initially required oxygen, two worsened and required oxygen at the second assessment. Among the two $\mathrm{HC}$ who did not initially require enteral nutrition, one required nutritional support at the second assessment. In HC, repetitive WLL and steroids did not lead to significant improvement in chest CT images and BAL fluid composition as illustrated in Figure 2 for two patients. The patient presented in Figure 2A was diagnosed at 5 months of age. Chest CT and BAL are presented at diagnosis and six months later after 9 WLL. By that time, he was dependent on oxygen and NIV. He is currently 8.5 years old and still required oxygen and nocturnal NIV. The patient presented in Figure 2B was diagnosed at 3 months of age. Chest CT and BAL are presented 12 months later after 18 WLL and 7 series of IV steroid pulses. By that time, he was dependent on oxygen. He died one month later. Regarding other 
clinical and biological features, differences between values at M0 and M6-M12 were statistically significant between $\mathrm{HC}$ and treated patients for respiratory rate $(\mathrm{p}=0.025)$, blood neutrophils ( $\mathrm{p}=0.034)$, AST $(\mathrm{p}=0.004)$ and GGT $(\mathrm{p}=0.038) \quad$ (Supplemental Figure S2), showing a greater improvement of these parameters for patients treated with methionine than for the HC. These results suggest efficacy of methionine not only in improving the respiratory status but also inflammation, nutrition, and liver status.

\section{SAFETY OF THE TREATMENT}

Methionine supplementation was well tolerated during the protocol and after. Nausea and vomiting occurred in the four patients but pre-existed the treatment and stopped after initiation of it. P3 presented initially mild elevated transaminases (Tables 1 and 2), which normalized on D5 of treatment. On D21 she presented a new episode of elevated transaminases $(>3 N)$, and a reappearance of vomiting, feeding difficulties and weight loss. Infectious work-up was negative. These alterations were associated to a parallel rapid decrease in methionine plasma concentration probably explained by a rapid weight gain $(+500$ g between D1 and D21 of treatment, i.e., a $12.5 \%$ increase in the patient's weight). As liver failure with elevated transaminases is itself one of the features of MARS1 related PAP, the observed decrease in methionine plasma level was hypothesized to be actually the cause of these alterations. A complementary analysis of the literature found data supporting this hypothesis: in animal models, methionine restriction induces steatohepatitis [14-16]. Methionine doses were increased and resulted in an increase in methionine plasma levels, along with a rapid improvement in AST and ALT values, resolution of vomiting, resumption of oral feeding, and weight gain. No recurrence of elevated transaminases has occurred since. Plasma homocysteine never reached the threshold of $30 \mu \mathrm{M}$ for any of the patients. 


\section{CELLULAR ASSAYS}

MetRS protein levels in PBMCs of P1 before starting methionine were normal relative to those of a control individual (Supplemental Figure S2). GM-CSF priming of ROS production by peripheral monocytes was measured in P1 and P3. It was low at baseline and improved after 3 months of supplementation with methionine (Supplemental Figure S2).

\section{DISCUSSION}

We report the results of supplementation with methionine for PAP and multi-organ dysfunction caused by hereditary MetRS deficiency. The treatment led to an important improvement in clinical, laboratory, imaging, and pathological parameters and was well tolerated. Peripheral monocytes showed an initially altered function that improved under treatment.

Drawing on our preliminary results [3], two other groups reported methionine use in patients harbouring other MARS1 mutations. In the case reported by Rips et al., methionine supplementation was briefly mentioned as leading to a clinical improvement but no details on the administration modality, doses, plasma concentrations, or potential cellular assays were provided [17]. Lenz et al. recently published a report on two brothers [18]. Although they provide some data on the doses and plasma concentrations of methionine, they are insufficient to assume that methionine plasma levels were within the target range during 24-hour periods or for days or months of treatment. The index case simultaneously received methionine and other treatments (IV immunoglobulins, hydroxychloroquine, steroids and antibiotics). No chest CT nor BAL examination comparing before and after treatment is given. His older brother was diagnosed during familial screening but was pauci-symptomatic. The efficacy of methionine supplementation is thus difficult to determine from these articles. The publication 
of isolated case reports reflects the difficulty of drawing powerful conclusions for therapeutic innovations in this orphan disease.

Almost all patients harbouring the "Réunion" mutations have been followed in our reference centre, allowing precise comparison of the treated patients to historical controls. Collected data were compared to patients that had had the standard of care for this disease, including repetitive WLL. Such a comparison showed significant differences in the evolution of respiratory, nutritional, liver and inflammatory status. P1 and P3 are the first to attain complete respiratory remission at their age. The relapse of hepatic and digestive signs in P3 when methionine plasma concentration decreased and the disappearance of those symptoms once plasma concentrations reached the target range again also argue for the accountability of methionine supplementation on the favourable outcome in the treated patients.

The small sample size and the heterogeneity of the four patients are limitations of this study. MARS1 related PAP is a rare disease with an incidence of 1 in 10,000 new-borns in Réunion and nearby, and only a few case-reports have described this disease in other ethnic groups [3, 5-10], explaining the small sample size. P2 and P4 did not achieve complete remission of their liver involvement at the last follow-up with a persistent enlarged liver. Treatment was started later than for P1 and P3. This can explain, in part, the discrepancy in their responses to treatment. A prospective follow-up of these patients and the treatment of other children will make it possible to determine the best scheme for treatment and predict its efficacy at various stages of the disease. The results obtained for P1 and P3 argue for starting methionine supplementation as soon as possible.

One strength of this study is the correction of the phenotype at the cellular level by the methionine supplementation. As for other forms of PAP, MARS1 mutations are hypothesized to induce alveolar macrophage dysfunction, leading to altered pulmonary surfactant metabolism. However, this has not yet been proven. We thus quantified the oxidative burst by 
the peripheral blood monocytes from two patients, as this would provide indirect information on alveolar macrophage function. Priming of ROS production by monocytes was very low before treatment and improved after three months of treatment. These results are the first to suggest macrophage dysfunction subsequent to MARS1 mutations and to show such an improvement after treatment.

Tolerance of the treatment was good, consistent with studies on congenital hypermethioninemia, which did not reveal toxicity at the plasma methionine concentrations observed in our study [11, 19]. Oral intake at fixed intervals resulted in stable blood concentrations within each patient. In the era of personalized medicine, which promotes the development of costly and highly specific targeted drugs, L-methionine is highly affordable. WLL, which remains currently the standard of care for these patients, is a heavy and risky procedure performed under general anaesthesia and requires repetitive hospitalizations. In addition, this treatment has never enabled complete remission in the past and appears to have no influence on the long-term prognosis [2]. Thus, methionine appears to be a highly promising and cost-effective treatment.

This study paves the way for similar strategies for other ARS deficiencies. Fuchs et al. reviewed 112 patients with diverse ARS deficiencies that share common features, including lung and liver disease and failure to thrive [20]. The authors proposed a pathophysiological model in which disorders result from insufficient aminoacylation activity to meet translational demand in specific organs. They already suggested supplying the corresponding amino acid for each specific ARS deficiency as a therapeutic approach. Our results provide a first proof of concept for this strategy.

In conclusion, oral methionine supplementation in four children with PAP and multisystemic dysfunction related to MARS1 mutations led to full remission of the disease in two patients and a clear ongoing improvement in the two others. These promising results will 
fundamentally change the prognosis of this severe and often fatal disease. They also offer promising therapeutic perspectives for similar strategies in other ARS deficiencies. 


\section{ACKNOWLEDGMENTS}

We thank Christophe Merlette, the technical director of the mass spectrometry platform at Necker Hospital, for his invaluable contribution to the efficient implementation of the study. We thank Dr Laurent Enaud, who has been long involved in the care of numerous families with this disease on the island of Réunion.

We thank Dr Joel Schlatter, Dr Sylvain Auvity, and the pharmaceutical assistants from the Pharmacie Hospitalière at Necker Hospital for preparation of the methionine capsules.

Finally, we thank the patients and their families for their participation.

\section{AUTHORS CONTRIBUTIONS}

AH, DD, CPo, MMHN, JEB, MS, TJM, LB, CO, JMT, JdB and CD contributed to the conception and design of the study, the acquisition, analysis and interpretation of data for the study.

LA, EG, CPe, CV, FL and SR contributed to the acquisition of the data for the study and revised the draft of the manuscript.

$\mathrm{AH}, \mathrm{DD}$, and CD drafted the work and revising it after revision by the other authors. All authors approved the final version to be published.

\section{CONFLICT OF INTEREST}

A Hadchouel reports grant from La Fondation du Souffle et le Fonds de Recherche en Santé Respiratoire (SRC2017) and La Cellule Recherche et Innovation de l'APHP, Hôpital Necker. A Hadchouel has a patent EP 21305689.8 pending.

\section{SUPPORT STATEMENT}

This work was funded by La Fondation du Souffle et le Fonds de Recherche en Santé Respiratoire (SRC2017) and La Cellule Recherche et Innovation de l'APHP, Hôpital Necker. 


\section{REFERENCES}

1. Rosen SH, Castleman B, Liebow AA. Pulmonary alveolar proteinosis. N. Engl. J. Med. 1958; 258: 1123-1142.

2. Enaud L, Hadchouel A, Coulomb A, Berteloot L, Lacaille F, Boccon-Gibod L, Boulay V, Darcel F, Griese M, Linard M, Louha M, Renouil M, Rivière J-P, Toupance B, Verkarre V, Delacourt C, de Blic J. Pulmonary alveolar proteinosis in children on La Réunion Island: a new inherited disorder? Orphanet J. Rare Dis. 2014; 9: 85.

3. Hadchouel A, Wieland T, Griese M, Baruffini E, Lorenz-Depiereux B, Enaud L, Graf E, Dubus JC, Halioui-Louhaichi S, Coulomb A, Delacourt C, Eckstein G, Zarbock R, Schwarzmayr T, Cartault F, Meitinger T, Lodi T, de Blic J, Strom TM. Biallelic Mutations of Methionyl-tRNA Synthetase Cause a Specific Type of Pulmonary Alveolar Proteinosis Prevalent on Réunion Island. Am. J. Hum. Genet. 2015; 96: 826-831.

4. Comisso M, Hadchouel A, de Blic J, Mirande M. Mutations in MARS identified in a specific type of pulmonary alveolar proteinosis alter methionyl-tRNA synthetase activity. FEBS J. 2018; 285: 2654-2661.

5. van Meel E, Wegner DJ, Cliften P, Willing MC, White FV, Kornfeld S, Cole FS. Rare recessive loss-of-function methionyl-tRNA synthetase mutations presenting as a multiorgan phenotype. BMC Med. Genet. 2013; 14: 106.

6. Sun Y, Hu G, Luo J, Fang D, Yu Y, Wang X, Chen J, Qiu W. Mutations in methionyltRNA synthetase gene in a Chinese family with interstitial lung and liver disease, postnatal growth failure and anemia. J. Hum. Genet. 2017; 62: 647-651.

7. Rips J, Meyer-Schuman R, Breuer O, Tsabari R, Shaag A, Revel-Vilk S, Reif S, Elpeleg O, Antonellis A, Harel T. MARS variant associated with both recessive interstitial lung and liver disease and dominant Charcot-Marie-Tooth disease. Eur. J. Med. Genet. 2018; 61: 616-620. 
8. Abuduxikuer K, Feng J-Y, Lu Y, Xie X-B, Chen L, Wang J-S. Novel methionyl-tRNA synthetase gene variants/phenotypes in interstitial lung and liver disease: A case report and review of literature. World J. Gastroenterol. 2018; 24: 4208-4216.

9. Alzaid M, Alshamrani A, Al Harbi A, Alenzi A, Mohamed S. Methionyl-tRNA synthetase novel mutation causes pulmonary alveolar proteinosis. Saudi Med. J. 2019; 40: 195-198.

10. Lenz D, Stahl M, Seidl E, Schöndorf D, Brennenstuhl H, Gesenhues F, Heinzmann T, Longerich T, Mendes MI, Prokisch H, Salomons GS, Schön C, Smith DEC, Sommerburg O, Wagner M, Westhoff JH, Reiter K, Staufner C, Griese M. Rescue of respiratory failure in pulmonary alveolar proteinosis due to pathogenic MARS1 variants. Pediatr. Pulmonol. 2020; 55: 3057-3066.

11. Chien Y-H, Abdenur JE, Baronio F, Bannick AA, Corrales F, Couce M, Donner MG, Ficicioglu C, Freehauf C, Frithiof D, Gotway G, Hirabayashi K, Hofstede F, Hoganson G, Hwu W-L, James P, Kim S, Korman SH, Lachmann R, Levy H, Lindner M, Lykopoulou L, Mayatepek E, Muntau A, Okano Y, Raymond K, Rubio-Gozalbo E, Scholl-Bürgi S, Schulze A, Singh R, et al. Mudd's disease (MAT I/III deficiency): a survey of data for MAT1A homozygotes and compound heterozygotes. Orphanet J. Rare Dis. 2015; 10: 99.

12. Garlick PJ. Toxicity of methionine in humans. J. Nutr. 2006; 136: 1722S-1725S.

13. Mudd SH. Hypermethioninemias of genetic and non-genetic origin: A review. Am. J. Med. Genet. C Semin. Med. Genet. 2011; 157C: 3-32.

14. Oz HS, Chen TS, Neuman M. Methionine deficiency and hepatic injury in a dietary steatohepatitis model. Dig. Dis. Sci. 2008; 53: 767-776.

15. Matsumoto M, Hada N, Sakamaki Y, Uno A, Shiga T, Tanaka C, Ito T, Katsume A, Sudoh M. An improved mouse model that rapidly develops fibrosis in non-alcoholic steatohepatitis. Int. J. Exp. Pathol. 2013; 94: 93-103. 
16. Peng JL, Bai SP, Wang JP, Ding XM, Zeng QF, Zhang KY. Methionine deficiency decreases hepatic lipid exportation and induces liver lipid accumulation in broilers. Poult. Sci. 2018; 97: 4315-4323.

17. Rips J, Meyer-Schuman R, Breuer O, Tsabari R, Shaag A, Revel-Vilk S, Reif S, Elpeleg O, Antonellis A, Harel T. MARS variant associated with both recessive interstitial lung and liver disease and dominant Charcot-Marie-Tooth disease. Eur. J. Med. Genet. 2018; 61: 616-620.

18. Lenz D, Stahl M, Seidl E, Schöndorf D, Brennenstuhl H, Gesenhues F, Heinzmann T, Longerich T, Mendes MI, Prokisch H, Salomons GS, Schön C, Smith DEC, Sommerburg O, Wagner M, Westhoff JH, Reiter K, Staufner C, Griese M. Rescue of respiratory failure in pulmonary alveolar proteinosis due to pathogenic MARS1 variants. Pediatr. Pulmonol. 2020; 55: 3057-3066.

19. Garlick PJ. Toxicity of methionine in humans. J. Nutr. 2006; 136: 1722S-1725S.

20. Fuchs SA, Schene IF, Kok G, Jansen JM, Nikkels PGJ, van Gassen KLI, TerheggenLagro SWJ, van der Crabben SN, Hoeks SE, Niers LEM, Wolf NI, de Vries MC, Koolen DA, Houwen RHJ, Mulder MF, van Hasselt PM. Aminoacyl-tRNA synthetase deficiencies in search of common themes. Genet. Med. 2019; 21: 319-330. 
Table 1. Patient characteristics at baseline

\begin{tabular}{|c|c|c|c|c|}
\hline & $\mathrm{P} 1$ & $\mathrm{P} 2$ & P3 & $\mathrm{P} 4$ \\
\hline Ethnic origin & Réunion & Mayotte & Réunion & Comoros \\
\hline Gender & Girl & Girl & Girl & Boy \\
\hline Age at diagnosis (months) & 4 & 5 & 3 & 3 \\
\hline Age at treatment's initiation (months) & 6 & 35 & 6 & 21 \\
\hline Respiratory status & & & & \\
\hline Oxygen dependency & Yes & No & Yes & Yes \\
\hline Ventilatory support & No & No & No & Yes \\
\hline Growth and nutrition & & & & \\
\hline Weight (SD) & $4.2(-3.4)$ & $14.9(+1)$ & $4.1(-3.7)$ & $8.4(-2.7)$ \\
\hline Regimen & $\begin{array}{l}\text { Enteral }(65 \%) \\
+ \text { Oral }(35 \%)\end{array}$ & $\begin{array}{l}\text { Complete enteral } \\
\text { nutrition }\end{array}$ & $\begin{array}{l}\text { Enteral }(70 \%) \\
+ \text { Oral }(30 \%)\end{array}$ & Complete parenteral nutrition \\
\hline Vomiting & Yes & Yes & Yes & Yes \\
\hline $\begin{array}{l}\text { Neurodevelopmental assessment } \\
\text { Clinical impairment }\end{array}$ & Yes, hypotonia & No & Yes, hypotonia & $\begin{array}{l}\text { Yes, sat with support, } \\
\text { vocalizes syllables, no words }\end{array}$ \\
\hline Brain MRI* & Normal & Periventricular cysts & Periventricular cysts & Normal \\
\hline $\begin{array}{l}\text { Liver status } \\
\text { Enlarged liver } \\
\text { Elevated AST/ALT } \\
\text { Elevated GGT }\end{array}$ & $\begin{array}{l}\text { Yes } \\
\text { Yes } \\
\text { Yes }\end{array}$ & $\begin{array}{l}\text { Yes } \\
\text { No } \\
\text { No }\end{array}$ & $\begin{array}{l}\text { Yes } \\
\text { Yes } \\
\text { Yes }\end{array}$ & $\begin{array}{l}\text { Yes } \\
\text { No } \\
\text { Yes }\end{array}$ \\
\hline $\begin{array}{l}\text { Haematological status } \\
\text { Anaemia } \\
\text { High neutrophils' count } \\
\text { Thrombocytosis }\end{array}$ & $\begin{array}{l}\text { Yes } \\
\text { Yes } \\
\text { Yes }\end{array}$ & $\begin{array}{l}\text { No } \\
\text { No } \\
\text { No }\end{array}$ & $\begin{array}{l}\text { Yes } \\
\text { Yes } \\
\text { No }\end{array}$ & $\begin{array}{l}\text { Yes } \\
\text { Yes } \\
\text { No }\end{array}$ \\
\hline Inflammation $^{\ddagger}$ & Yes & Yes & Yes & Yes \\
\hline $\begin{array}{l}\text { Daily methionine intake at baseline }(\mathrm{mg}) \\
\text { Fasting methionine plasma concentration }(\mu \mathrm{M})^{\dagger}\end{array}$ & $\begin{array}{l}231 \\
18\end{array}$ & $\begin{array}{l}650 \\
33\end{array}$ & $\begin{array}{l}256 \\
13\end{array}$ & $\begin{array}{l}297 \\
23\end{array}$ \\
\hline
\end{tabular}


Table 2: Disease course under methionine supplementation

\begin{tabular}{|c|c|c|c|c|c|c|c|c|c|c|c|c|}
\hline & \multicolumn{3}{|c|}{ P1 } & \multicolumn{3}{|c|}{$\mathrm{P} 2$} & \multicolumn{3}{|c|}{ P3 } & \multicolumn{3}{|c|}{$\mathrm{P} 4$} \\
\hline & $\begin{array}{c}\text { D0 } \\
6 \text { months }\end{array}$ & M2 & $\begin{array}{c}\text { LFU } \\
19 \text { months }\end{array}$ & $\begin{array}{c}\mathrm{D} 0 \\
3 \text { years }\end{array}$ & M2 & $\begin{array}{c}\text { LFU } \\
4.5 \text { years }\end{array}$ & $\begin{array}{c}\text { D0 } \\
6 \text { months }\end{array}$ & M2 & $\begin{array}{c}\text { LFU } \\
16 \text { months }\end{array}$ & $\begin{array}{c}\text { D0 } \\
21 \text { months }\end{array}$ & M2 & $\begin{array}{c}\text { LFU } \\
33 \text { months }\end{array}$ \\
\hline \multicolumn{13}{|l|}{ Clinical features } \\
\hline Weight (kg) (SD) & $4.2(-3.4)$ & $4.9(-3.3)$ & $10.2(0)$ & $14.9(+1)$ & $15(+1)$ & $17.3(+1)$ & $4(-3.7)$ & $5.3(-3)$ & $8.4(-1.6)$ & $8.4(-2.7)$ & $10(-1.5)$ & $10.6(-2)$ \\
\hline $\begin{array}{l}\text { Respiratory rate } \\
\text { (cycles/min) }\end{array}$ & 70 & 32 & 32 & 28 & 24 & 18 & 60 & 55 & 27 & 65 & 65 & 42 \\
\hline Oxygen dependency & $1 \mathrm{~L} / \mathrm{min}$ & No & No & No & No & No & $0.5 \mathrm{~L} / \mathrm{min}$ & No & No & $\begin{array}{l}2-4 \mathrm{~L} / \mathrm{min} \\
+\mathrm{c}-\mathrm{NIV}\end{array}$ & $\begin{array}{l}\mathrm{D}: 0.5 \mathrm{~L} / \mathrm{min} \\
\mathrm{N}: 0.8 \mathrm{~L} / \mathrm{min}\end{array}$ & No \\
\hline Nutritional regimen & $\begin{array}{l}65 \% \mathrm{E} \\
35 \% \mathrm{O}\end{array}$ & $100 \% \mathrm{O}$ & $100 \% \mathrm{O}$ & $100 \% \mathrm{E}$ & $\begin{array}{l}80 \% \mathrm{E} \\
20 \% \mathrm{O}\end{array}$ & $\begin{array}{l}35 \% \mathrm{E} \\
65 \% \mathrm{O}\end{array}$ & $\begin{array}{l}70 \% \mathrm{E} \\
30 \% \mathrm{O}\end{array}$ & $\begin{array}{l}35 \% \mathrm{E} \\
65 \% \mathrm{O}\end{array}$ & $100 \% \mathrm{O}$ & $100 \% \mathrm{P}$ & $\begin{array}{l}80 \% \mathrm{P} \\
20 \% \mathrm{E}\end{array}$ & $\begin{array}{l}70 \% \mathrm{E} \\
30 \% \mathrm{O}\end{array}$ \\
\hline Nausea / vomiting & Yes & No & No & Yes & No & No & Yes & No & No & Yes & No & No \\
\hline $\begin{array}{l}\text { Psychomotor } \\
\text { impairment } \\
\text { Biological features }\end{array}$ & Hypotonia & None & None & None & None & None & Hypotonia & None & None & $\begin{array}{l}\text { Important } \\
\text { delay }\end{array}$ & $\begin{array}{l}\text { Sat alone, said } \\
\text { a few words }\end{array}$ & Walks \\
\hline Haemoglobin $(\mathrm{g} / \mathrm{dL})$ & 9.1 & 10.4 & 11.7 & 11 & 11.3 & 11 & 8.7 & 10.1 & 10.8 & 9.2 & 9.3 & 11.5 \\
\hline Leucocytes $\left(/ \mathrm{mm}^{3}\right)$ & 31,700 & 5,100 & 6,900 & 6,400 & 9,200 & 8,300 & 20,900 & 13,500 & 15,700 & 18,820 & 8,200 & 7,700 \\
\hline Neutrophils $\left(/ \mathrm{mm}^{3}\right)$ & 18,100 & 1,900 & 1,400 & 1,700 & 4,500 & 2,400 & 11,200 & 3,100 & 3,300 & 14,490 & 3,100 & 2,200 \\
\hline Platelets $\left(/ \mathrm{mm}^{3}\right)$ & 668,000 & 218,000 & 339,000 & 157,000 & 235,000 & 252,000 & 441,000 & 565,000 & 406,000 & 189,000 & 183,000 & 165,000 \\
\hline $\begin{array}{l}\text { Sedimentation rate } \\
(\mathrm{mm})\end{array}$ & 56 & 46 & 25 & 11 & 7 & 7 & 87 & 43 & 58 & 34 & 27 & 44 \\
\hline $\mathrm{CRP}(\mathrm{mg} / \mathrm{L})$ & 53.8 & 8.3 & $<5$ & $<5$ & $<5$ & $<5$ & 15.8 & $<5$ & $<5$ & 71.4 & $<5$ & $<5$ \\
\hline $\operatorname{IgG}(\mathrm{g} / \mathrm{L})$ & 21.52 & 10.94 & 8.03 & 9.23 & 10.89 & 8.68 & 18.03 & 11.3 & 13.93 & 15.07 & 11.32 & 13.34 \\
\hline Albumin $(\mathrm{g} / \mathrm{L})$ & 23.2 & 38.4 & 42.3 & 38 & 44.2 & 37.1 & 28.7 & 43 & 45.2 & 6 & 26.5 & 30 \\
\hline Prothrombin rate (\%) & 54 & 71 & 86 & 91 & 85 & 92 & 72 & 85 & 82 & 81 & 71 & 80 \\
\hline AST (IU/L) & 81 & 44 & 52 & 45 & 28 & 31 & 101 & 51 & 48 & 50 & 108 & 57 \\
\hline ALT (IU/L) & 23 & 16 & 25 & 28 & 22 & 23 & 65 & 29 & 22 & 7 & 44 & 24 \\
\hline GGT (IU/L) & 64 & 44 & 13 & 16 & 17 & 12 & 406 & 18 & 16 & 198 & 214 & 71 \\
\hline $\mathrm{T}$ bilirubin $(\mu \mathrm{M})$ & 47 & 4 & 4 & 4 & 4 & 4 & 4 & 3 & 2 & 30 & 13 & 4 \\
\hline $\mathrm{C}$ bilirubin $(\mu \mathrm{M})$ & 36 & 2 & 0 & 0 & 0 & 0 & 4 & 0 & 0 & 13 & 0 & 0 \\
\hline \multicolumn{13}{|l|}{ Other treatments } \\
\hline WLL & + & - & - & + & - & - & + & - & - & + & - & - \\
\hline Steroids & - & - & - & - & - & - & - & - & - & + & - & - \\
\hline MMF & - & - & - & + & + & - & - & - & - & - & - & - \\
\hline
\end{tabular}

SD: standard deviation. D: day. N: night. NIV: non-invasive ventilation. M2: month 2. LFU: last follow-up. 


\section{FIGURE LEGENDS:}

Figure 1. Comparison of imaging and pathological data before and after supplementation with methionine.

Panels 1 and 2: CT and BALF images for Patients 1 (P1) and 3 (P3) respectively. A: CT at diagnosis. B: CT at the last follow-up. C-F: Pathological aspects of BALF. C and E: first WLL. D and F: last BAL. C-D: Periodic Acid Schiff staining (PAS), 100x. E-F: Oil Red O (ORO) staining, 200x.

Panel 1. A: The CT, that was performed very early in the course of the disease, showed discrete lesions with anterior hyperinflation, low-density ground-glass opacities, intralobular lines, and thickened interlobular septa with an anteroposterior density gradient. B: After 13 months of treatment the CT showed a disappearance of the crazy paving pattern. C-D: PAS staining showed the complete disappearance of the abnormal extra-cellular lipoproteinaceous material, highly present before treatment, after three months of supplementation. E-F: This was associated with a decrease in total cellularity of the fluid and in the number of OROpositive macrophages, ranging from $100 \%$ before to $13 \%$ under treatment at D90.

Panel 2: A: The CT showed diffuse ground-glass opacities, thickened interlobular septa and intralobular lines (crazy paving pattern), with an increasing gradient of density in posterior and inferior areas. B: After 11 months of treatment the CT showed a clear improvement, with complete regression of the subpleural pseudonodular consolidations and of the crazy paving pattern. A subtle crazy-paving pattern of very low-density remained. C-D: PAS staining showed partial regression of the abnormal extra-cellular lipoproteinaceous material, highly present before treatment, after five months of supplementation. E-F: This was associated with a decrease in cellularity of the fluid and in the number of ORO-positive macrophages ranging from $90 \%$ before to $7 \%$ after 5 months of treatment. 
Panel 3, Patient 2 (P2): A: Chest CT before starting methionine but after 25 WLL, several series of methylprednisolone pulses and 15 months of treatment with mycophenolate mofetil, showed no specific lesion apart from discrete ground glass opacities that could be related to breathing movements. B: chest CT performed after 18 months of supplementation with methionine and after 6 months of MMF arrest showed no specific lesion and especially no sign of fibrosis.

Panel 4, Patient 4 (P4): A: Chest CT before starting methionine but after 19 WLL and 4 series of methylprednisolone pulses, showed a crazy-paving appearance with an increasing gradient of density in the posterior and inferior areas, along with sub-pleural and intra-parenchymal microcystic lesions. B: A chest CT performed after 12 months of supplementation with methionine showed an important regression of consolidations. Microcystic lesions remained stable. Met: methionine. Suppl.: supplementation.

Figure 2. Chest CT and pathological images for historical controls.

A: Chest CT images and PAS staining of BALF from a five-month-old boy at diagnosis (left panel) and six months later (right panel) after 9 WLL. Chest CT and BAL images show worsening of consolidations and an increasing amount of PAS positive material over time, respectively. B: Chest CT images and PAS staining of BALF for a three-month-old boy at diagnosis (left panel) and 12 months later (right panel) after 18 WLL and seven series of IV steroid pulses. Chest CT images show the persistence of the crazy-paving pattern, with partial regression of consolidations and the appearance of signs of fibrosis with microcystic lesions. BAL cytological analyses show the persistence of abundant extracellular and intramacrophage PAS positive material. WLL: whole lung lavages. 